\title{
How do R\&D employees use their social networks to acquire user information?
}

How do R\&D employees use their social networks to acquire user information?

Author Details (please list these in the order they should appear in the published article)

Author 1 Name: Carl Wadell

Role: $\mathrm{PhD}$ candidate

Department: IPD, School of Industrial Engineering and Management

University/Institution: KTH Royal Institute of Technology

Town/City: Stockholm

State (US only):

Country: Sweden

Author 2 Name: Jennie Björk

Role: Researcher (PhD)

Department: IPD, School of Industrial Engineering and Management

University/Institution: KTH Royal Institute of Technology

Town/City: Stockholm

State (US only):

Country: Sweden

Author 3 Name: Mats Magnusson

Role: Full professor

Department: IPD, School of Industrial Engineering and Management

University/Institution: KTH Royal Institute of Technology

Town/City: Stockholm

State (US only):

Country: Sweden

NOTE: affiliations should appear as the following: Department (if applicable); Institution; City; State (US only); Country. No further information or detail should be included

\section{Corresponding author: Carl Wadell \\ Corresponding Author's Email: cwadell@kth.se}

Please check this box if you do not wish your email address to be published

Acknowledgments (if applicable): The work presented in this article has been financed by the Swedish Governmental Agency for Innovation Systems VINNOVA.

\section{Biographical Details (if applicable):}

Carl Wadell is a Doctoral candidate at Integrated Product Development at KTH Royal Institute of Technology in Stockholm, Sweden. His research focuses on user-centered innovation in medical technology firms.

Jennie Björk $(\mathrm{PhD})$ is a researcher at Integrated Product Development at KTH Royal Institute of Technology in Stockholm, Sweden. Her main research interests are ideation, ideation management, knowledge sharing, knowledge creation and social networks. She has recently published her work in

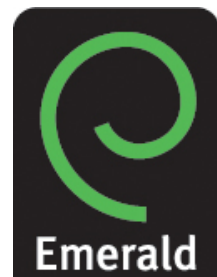


journals such as Creativity and Innovation Management, the Journal of Product Innovation Management, and Industry \& Innovation.

Mats Magnusson is a Full Professor in Product Innovation Engineering at KTH Royal Institute of Technology in Stockholm, Sweden, and director of the Institute for Management of Innovation and Technology. He has been a Visiting Professor at Luiss Guido Carli University in Rome, the University of Bologna, and Aalborg University and is also the Chairman of the Continuous Innovation Network (CINet). His research focuses on continuous innovation, strategic management, ideation, and the management of knowledge and learning. He has published numerous articles on these topics in various journals, including the Journal of Product Innovation Management, Research Policy, and Long Range Planning.

\section{Structured Abstract:}

\section{Purpose}

The aim of this article is to investigate how R\&D employees use their social networks to acquire user information and how this information is used in the development of new products.

\section{Design/methodology/approach}

A single case study was conducted within a business unit at a multinational medical technology company. Data was collected through a mixed method.

\section{Findings}

The results show that many R\&D employees lack social networks through which they can acquire information about the users' needs. However, some R\&D employees' establish cost-efficient relationships to people with a direct experience of using the company's products. These relationships are established over time and are often used in a rather informal way to acquire user information. Moreover, the results show how R\&D employees are purposefully complementing these relationships with more occasional interactions with people that hold direct and indirect use experiences.

\section{Research limitations/implications (if applicable)}

As with most single case studies, it will be important to replicate this investigation in other contexts in order to clarify the generalizability of the findings.

\section{Practical implications (if applicable)}

The article shows how important it is that management provides R\&D employees with opportunities to establish, nurture, and utilize relationships conducive to information about the users' needs, The article provides some advice on how this can be accomplished.

\section{Originality/value}

This is one of the first articles that clearly explain how R\&D employees use their social networks to acquire user information for the development of new products.

Keywords: User information, Social networks, R\&D, New product development, Medical technology

\section{Article Classification: Research article}




\section{Introduction}

Timely and reliable information about users' needs and priorities is one of the most critical types of information in new product development (Adams et al., 1998; Bacon et al., 1994). Indeed, Research and Development (hereinafter R\&D) employees in companies with high innovation performance have a better understanding of users' needs than R\&D employees in less successful companies (e.g. Cooper and Kleinschmidt, 1994). At the same time, previous research reveals that this particular information can be costly and difficult to transfer from users to company employees (von Hippel, 1994). The problem of transferring user information may be caused by the nature of the information, the quantities of information that need to be transferred, or that the company in question lack absorptive capacity (Bogers et al., 2010). Consequently, practitioners and researchers alike have invested much time and resources in finding new and better ways to provide R\&D employees with timely and reliable information about the users' needs and priorities.

Much of these efforts have focused on developing various methods and tools that companies can use to identify, access, and involve users in new product development projects (Lüthje and Herstatt, 2004; Cooper and Edgett, 2008;). Another stream of research has focused on understanding the more general interaction patterns with users in new product development projects (Gales and Mansour-Cole, 1995; Gruner and Homburg, 2000). There is also research that has investigated how market information is integrated in R\&D units (Griffin and Hauser, 1996; Adams et al., 1998; Leenders and Wierenga, 2002). However, neither of these literature streams explicitly focuses on how R\&D employees use their social networks to acquire information about the users' needs and how they use this information in the development of new products. This is noteworthy since social interaction and face-to-face communication are essential means to transfer information between people. It is even argued that the most efficient mechanisms for information sharing are the social networks that employees use in their everyday work (McDermott and O'Dell, 2001). The social network perspective has also been advocated by several scholars as it allows researchers to investigate, not only formal, but also informal relationships that people use to access information (Hansen, 1999; Cross and Parker, 2004). Even so, analyses of social networks within R\&D units remain relatively rare (Allen et al., 2007).

Consequently, the aim of this explorative article is to investigate how R\&D employees use their social networks to acquire user information and how they use this information in the development of new products. By doing so the article intends to contribute to a body of literature that concerns how companies can manage user information in new product development (e.g. Lüthje and Herstatt, 2004; Keinz et al., 2012). The article is structured as follows. The first section is a theoretical exposition that initially elaborates on how R\&D units influence companies' ability to absorb information about the users' needs. Thereafter the authors elaborate more specifically on how R\&D employees' search for information about the users' needs. After that the authors introduce literature that reveals how a social network perspective can help us to further understand how R\&D employees' acquire user information when developing new products. With this theoretical exposition as a base the research question of the study is presented. After that, the case company and the research methods used are introduced. The authors then present and discuss the results, relate them to the extant literature, and consider theoretical and managerial implications. Finally, some limitations of the study, as well as potential directions for future research are presented.

\section{Theoretical exposition}

\subsection{User information and R\&D}

One of the most central functional units in many innovating companies is R\&D (Dosi, 1988; Freeman and Soete, 2009). Apart from developing new knowledge and products, R\&D units have also been pointed out as highly important for companies ability to recognize the value of external information, assimilate it, and apply it to commercial ends (Cohen and Levinthal, 1990). However, recent research shows that companies may benefit from articulating different intra-organizational sources in order to absorb different types of external information (Volberda et al., 2010; Bogers and Lhuillery, 2012). In particular, it is argued that companies can benefit from considering so-called marketing-based absorptive capacity, which allows companies to learn about their customers and competitors. Indeed, a rather comprehensive body of literature shows that the integration between marketing and R\&D units play an important role in the development of new products (Griffin and Hauser, 1996; Leenders and Wierenga, 2002). More generally, it has been argued that the absorptive capacity of a company is dependent on employees' prior knowledge and experience (Cohen and Levinthal, 1990; Argote and Miron-Spektor, 2011). Adopting this definition it is noteworthy that previous literature on absorptive capacity appear to overlook companies' explicit ability to absorb information about the users' needs. Previous research shows that users often possess knowledge and experience related to a company's products that are distinctly different from the experience held by R\&D employees (von Hippel, 2005). In general, R\&D 
employees in established companies have a high degree of product- and manufacturing-related knowledge, i.e. knowhow about existing products' composition, technologies, materials, as well as manufacturing and production processes. The users, on the other hand, have experiences related to how the product helps them to accomplish what they want and the problems that they encounter during the use of the product. Hence, it can be assumed that the direct and indirect use experiences controlled by a company will influence its ability to acquire, disseminate, and utilize new information about the users' needs.

\subsection{R\&D employees' search for user information}

Previous research shows that timely and reliable information about users' needs is critical for the development of new products (Bacon et al., 1994; Adams et al., 1998). Users are often in a good position to evaluate the strengths and weaknesses of existing products and if a product does not satisfy their needs they can provide feedback on what functionalities or features that need to be added. Hence, it is not surprising that R\&D employees in companies with high innovation performance normally have a better understanding of the users' needs than R\&D employees in companies with low innovation performance (e.g. Cooper and Kleinschmidt, 1994). Even so, many companies struggle to provide their employees with timely and reliable information about users' needs and previous research shows that user information can be costly and difficult to transfer from users to company employees (von Hippel, 1994).

In order to face this challenge many companies are adopting new organizational designs and strategies for usercentered innovation (e.g. Keinz et al., 2012). This implies, among other things, that companies are elaborating on their competence bases, organizational structures, methods and tools, incentive systems, functional roles, and work tasks to leverage user knowledge. One essential aspect in order to be able to design such solutions is to understand how R\&D employees use their social networks to acquire information about the users' needs. Indeed, social interaction and face-to-face communication have been pointed out as highly important means to transfer this type of information (von Hippel, 1994). One reason why user information can be difficult to transfer is that it derives from the users knowledge that contains tacit components. This type of knowledge is rooted in peoples' actions, procedures, routines, commitments, ideals, values, and emotions and it can be difficult to convey (Nonaka et al. 1996).

In order to understand 'how' R\&D employees use their social networks to acquire this particular information it is essential to consider 'why' they should do so. One explanation why R\&D employees would do so is that they experience some sort of uncertainty or ambiguity related to the users' needs in the new product development process. Previous research shows that the level of uncertainty or ambiguity often is linked to the stage of the development process or to the type of task that an employee is solving. For instance, Gales and Mansour-Cole (1995) showed that managers working on novel projects pursued frequent interaction with potential users. Moreover, it has been found that successful innovation projects comprise more interaction with customers in the early stages and in the later stages (but not in the middle phase), than is the case for less successful projects (Gruner and Homburg, 2000). More generally, Schulze and Hoegl (2008) showed that socialization with colleagues and external actors was crucial in the concept phase of new product development.

However, the view that high levels of uncertainty and ambiguity drive employees to search for user information is not uncontested. For instance, Veryzer (1998) showed that R\&D employees working on more novel solutions frequently avoid searching for new user information as they experience that the vast majority of users cannot provide valuable feedback, and that their input could even increase the uncertainty and ambiguity in the project. This notion also finds support in other streams of the literature. For instance, Pfeffer and Salancik (1978) noted that interaction with individuals outside the firm might increase uncertainty because of their idiosyncratic behavior. Adams et al. (1998) found out that R\&D employees tend to focus on uncertainties related to technical problem-solving, ignoring uncertainties related to the users' needs. Moreover, they found that many employees had problems to identify and define suitable users to talk to. Hence, instead of trying to find out what the real problems are for the user R\&D employees relied on already available market information.

Adams et al. (1998) also made a number of interesting observations of R\&D employees that did not avoid uncertainties related to the users' needs. These employees had developed routines that also included the search for more novel information about the users' needs. Hence, they complemented their existing understanding of the market by interacting with different user groups and elaborating on various solutions. Moreover, they tended to have an open attitude towards other people and leveraged on the users' knowledge. Lettl (2007) made a similar observation revealing that some employees within established medical technology companies had developed certain user interaction competences which allowed them to access valuable user input. Furthermore, Wadell et al., (2013) showed that users that are employed and integrated in a business unit played several important roles in the acquisition, dissemination, and utilization of information about the users' needs. On a more general level it is proposed that the 
probability that individuals will seek information from another person depends on (1) their knowledge about what a person knows, (2) their ability to value what a person knows, (3) being able to gain timely access to that person's thinking; and (4) perceiving that seeking information from that person would not be too costly (Borgatti and Cross, 2003, p. 432).

This notion suggests that the relationships and social networks that R\&D employees possess might have a significant impact on how they search for information about users' needs and priorities. Indeed, it is argued that the most efficient mechanisms for information sharing are the social networks that employees use in their everyday work (McDermott and O'Dell, 2001). However, there is lack of studies that apply a social network perspective when researching R\&D units (Allen et al., 2007). Hence, this is an interesting lens to apply in order to further our understanding of how R\&D employees acquire information about the users' needs in the development of new products.

\subsection{Social networks as a means for R\&D employees to acquire user information}

Previous research reveals that employees' social networks are important for their learning and knowledge creation in biotechnology firms (Liebeskind et al., 1996). It is even argued that social networks are the most dominating knowledge-sharing concept among life science scientists (Lilleoere and Hansen, 2011). Moreover, the social network perspective has been advocated by several scholars as it allows researchers to investigate, not only formal, but also more informal relationships that people use to access information (Hansen, 1999; Cross and Parker, 2004). A central aspect when considering a persons social network is how many people the person knows, directly and indirectly, and how easily these persons can be accessed? For instance, von Hippel (1999) describes how R\&D employees often are aware of major market trends within their particular field and argues that they should use their social networks to identify those user that are on the leading edge of the market, working on the most challenging problems in a particular field.

Another aspect is the characteristics of social relationships and insights about what relationships are conducive to what types of information. Some scholars argue that novel information mainly origins from more peripheral relationships whereas closer relationships conserve already existing information (Granovetter, 1973; Krackhardt, 1992). Granovetter (1973) displays in his seminal work on job changers that people with many sporadic relationships where most likely to receive novel information that eventually resulted in a new job offering. He concludes that the maintenance of these weak relationships can be highly important to find new opportunities. Furthermore, Burt (2004) expands this view by displaying how managers in a brokerage position were more likely to express ideas, less likely to have ideas dismissed, and more likely to have ideas evaluated as valuable. This brokerage position implied that they had a large number of non-redundant relationships to other people. Existing theory thus suggests that sporadic relationships to many colleagues and users would be most beneficial to access and exploit valuable user information. However, an important notion is that the costs of managing numerous weak relationships can be high due to higher levels of superintendence and potential idiosyncrasies within relationships (Pfeffer and Salancik, 1978).

Nevertheless, other scholars argue that also strong relationships can be a source of novel information, especially if the transferred information is of a more complex and tacit nature. This has been shown in studies on the transfer of information and knowledge across departmental boundaries (Hansen, 1999). Moreover, it is argued that strong relationships are important since they are more accessible and willing to be helpful than weak relationships (Krackhardt, 1992). Moreover, frequent interactions may result in a reciprocal communication, which in turn may be associated with rich communication (Daft and Lengel, 1986). This type of user involvement has shown to be particularly important in solving misunderstandings or disagreements between users and developers (Lind and Zmud, 1991). Another important aspect of strong relationships is the presence of trust. Ahuja (2000) displayed that increased trust improved collaboration and reduced opportunistic behaviors. In general, people are more willing to both give and absorb useful knowledge if they feel trust to the other party (Zaheer et al., 1998). Hence, we hope to further our understanding of how R\&D employees establish and use their social networks to acquire user information in the development of new products. With this exposition of theory in mind, we formulate the following research question:

Research question: How do R\&D employees acquire user information through their social networks and how is this information used in new product development? 


\section{Methods used}

In order to address the explorative purpose of this study, we conducted a single case study within a large medical technology company. The background for the case selection was that the company participated in a longitudinal project together with several other companies, universities, and healthcare providers, aiming to improve collaboration between medical technology companies and healthcare providers, and thereby facilitate innovation. The study presented in this article was a subset of this project. There are several examples in the literature where single case studies within established medical technology companies have made important contributions to theory building (e.g. Lillien et al., 2002). In general, case studies have been shown to be appropriate for describing a phenomenon and building theory if the intention is to explore new areas (Eisenhardt, 1989). We adopted a mixed-method approach comprising a questionnaire and semi-structured interviews. This method was applied to gain a good overview of the R\&D employees' social networks through which they acquire user information, and at the same time develop a more in-depth understanding of the relationships that act as conduits for this information.

\subsection{Case study setting}

The case firm is a subsidiary of a multinational medical technology company headquartered in Sweden. The firm has existed for more than 25 years, employs approximately 380 people, and has an annual turnover of some $\$ 250$ million. The company has been a frontrunner in its field and over the last decades the company has introduced several innovative products. The study was conducted within one of the company's business units. Apart from R\&D, the business unit also included departments for marketing, sales, finance, aftermarket, operations, and quality and environmental affairs. The R\&D unit was divided into a product development group and a research group. Moreover, the business unit had a physician incorporated in the research group and a product application group with clinicians that worked closely with R\&D employees (see Wadell et al., 2013 for an analysis of the incorporated users role within the business unit). The development group included hardware and software developers, system architects, interaction designers, and test engineers. All R\&D employees worked in the same building.

\subsection{Data collection and analysis}

Data were collected in June 2010 (questionnaire) and March 2011 (semi-structured interviews), and the data-collection methods are summarized in Table 1. The questionnaire was designed to collect information about the employees' interactions with users, as well as their internal acquisition of user information. A paper-based questionnaire was handed to all 116 employees in the business unit. We received 86 completed questionnaires (75\% response rate). Of the 71 people employed in R\&D, 56 completed the questionnaire ( $79 \%$ response rate). To ensure the validity of the questions, a pilot test of the questionnaire was carried out on five R\&D employees prior the study. Based on the results of the survey, we selected 11 key informants with whom to conduct semi-structured interviews (see Table 2 for a more detailed description). These employees were selected either because they were highly central in the dissemination of user information or because they used very few sources of user information. Moreover, we selected employees in different functional roles and made sure that the selection allowed us to confirm some to the information transfers that had been indicated in the questionnaire. The interviewees were asked to describe in greater detail the ways that they acquired user information from the people they had indicated as sources in the questionnaire. Hence, the interviews allowed us to confirm the information transfer and achieve a better understanding of the respondents' questionnaire answers. In this way, we aimed to capture a wide range of perspectives on the usage of social networks for acquiring user information but in the same time derive a more in-depth understanding of relationships conducive to this particular information. We used an interview guide that also included general questions about each respondent's role within the firm and about how the firm works with issues of customer- and user involvement. The interviews were conducted in person and lasted approximately 60 minutes each. With the permission of the respondents, all interviews were recorded and later transcribed.

\begin{tabular}{ll}
\hline Method & Details \\
\hline $\begin{array}{l}\text { Phase 1 - Identifying user-information } \\
\text { acquisitions }\end{array}$ & $\begin{array}{l}\text { Paper-based questionnaire distributed to 116 } \\
\text { employees, in the business unit 86 responded } \\
(75 \% \text { response rate) }\end{array}$ \\
& $\begin{array}{l}\text { Out of 71 R\&D employees 56 completed the } \\
\text { questionnaire (79\% response rate) }\end{array}$ \\
\hline Phase 2 - Semi-structured interviews & $\begin{array}{l}\text { Recorded and transcribed interviews with R\&D } \\
\text { employees and internal clinicians (n = 11) }\end{array}$ \\
\hline
\end{tabular}




\section{Table 1 Data collection methods}

Regarding external user contacts, respondents were asked to indicate how frequently on average they had interacted with national and international physicians, nurses, clinical researchers, bio-engineers, and patients' family members in the previous three years. The frequency measures applied were never, yearly, monthly, once a week, a few times a week, daily, and do not know. The user groups were identified in collaboration with the marketing department. The patient group was not included in the survey since the patients are anesthetized when the company's products are being used. To capture data on internal dissemination, respondents were asked to indicate on a list of colleagues' names how frequently, on average, they had received valuable user information from particular colleagues over the last three years. In this case, the frequency measures were daily, weekly, monthly, and yearly. If respondents had received no valuable information, they were asked to leave a blank. Data were manually entered into MS Excel, where a common matrix for the internal and external flows was created. This matrix was then transformed to Ucinet 6 (Borgatti et al., 2002), which was used to draw graphs. All calculations were conducted in MS Excel. The results of each interview were summarized in short sections to provide a more in-depth understanding of how the different respondents acquired user information through their social networks.

\begin{tabular}{lll}
\hline Node & Formal position & Group \\
\hline & & \\
17 & Researcher & Research group \\
20 & Researcher & Research group \\
23 & Internal clinician & Research group \\
24 & Internal clinician & Product application \\
52 & Researcher & Research group \\
61 & Manager of product development & Product development \\
62 & Systems architect & Product development \\
64 & Interaction designer & Product development \\
70 & Systems architect & Product development \\
85 & Manager of product development & Product development \\
& Manager of product development & Product development \\
\hline
\end{tabular}

Table 2 Interviewee details

\section{Results}

The empirical results are presented in two parts. In the first section we present the results of the questionnaire and how the R\&D employees' interact with various user groups and acquire user information from their colleagues. In the second part we present the results from the interviews. Figure 1 illustrates means by which R\&D employees interact with different user groups and acquire user information from colleagues. Nodes in the diagram represent the individual members of the business unit as well as the focal user groups. The lines between business unit members and user groups represent interaction and the lines between unit members represent user information transfer. The more central a node is in the diagram, the more R\&D employees have indicated that they have interacted or acquired user information from that node. The diagram reveals that several employees in the product application and research group (nodes 20, 23, 24 and 25), were seen as a source of valuable user information by many R\&D colleagues. Other valuable sources of user information were national physicians and nurses (e.g. nodes 87 and 89 ), marketers (e.g. nodes 7, 9, 10, and 11), and some product developers (e.g. nodes 42, 62, and 64). A majority of the product developers has a rather peripheral position in the network diagram, i.e. they were not seen as sources of valuable user information by many R\&D colleagues. Moreover, apart from national nurses and physicians, the user groups (e.g. nodes $88,9091,92,93,94,95$, and 96) do not have a central position in the diagram. 


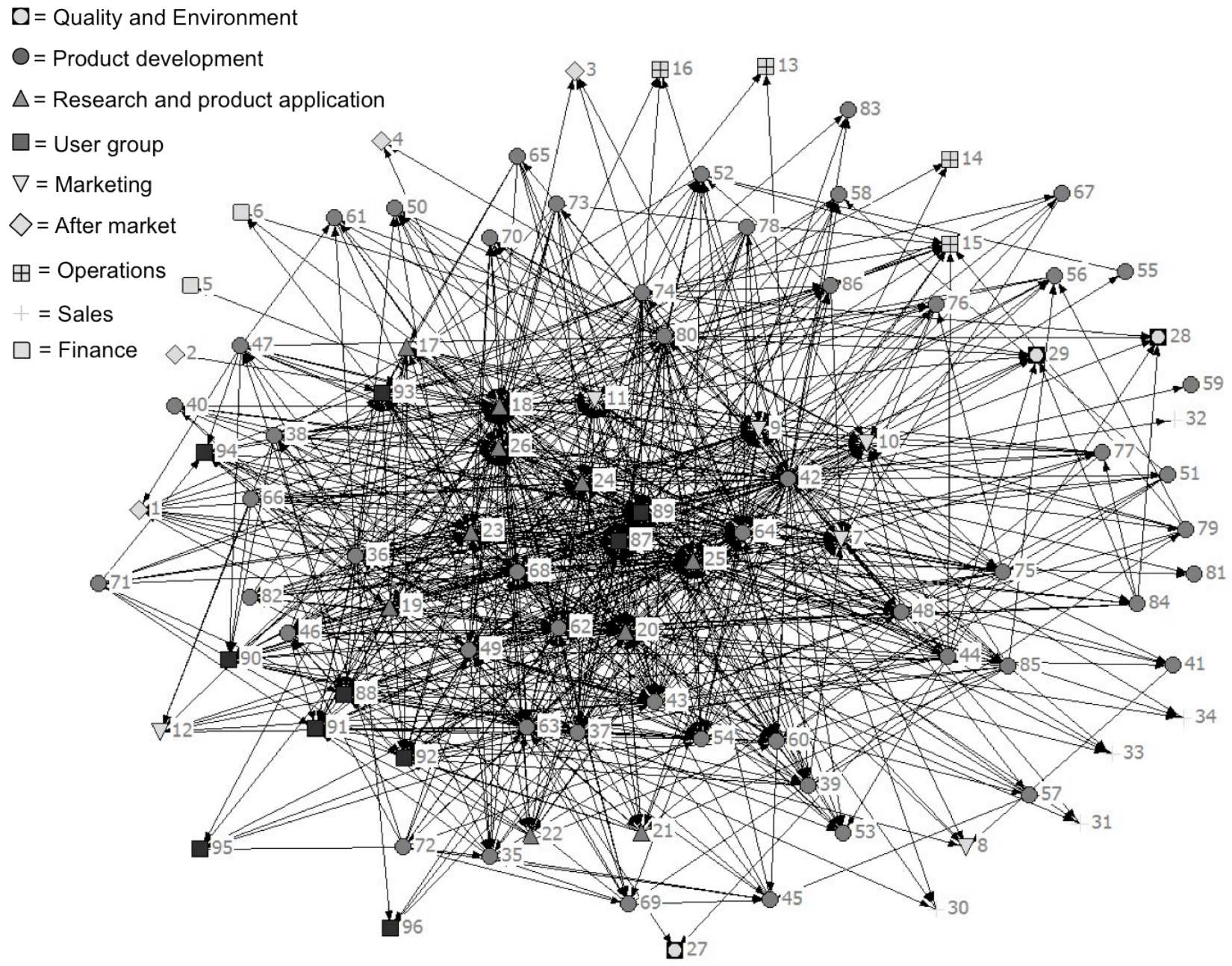

Figure 1 R\&D employees' acquisition of user information through their social networks

Following Allen (1977), we defined frequent acquisition as at least weekly user information acquisition/user group interaction (on average). This is seen as a fairly high level of consistent communication. Accordingly, less frequent acquisition was defined as monthly or yearly user information acquisition/ user group interaction. The analysis reveal that $41 \%$ of the R\&D employees experienced that they only have had less frequent acquisition of user information from user groups and colleagues. Another segment of R\&D employees (21.5\%) experienced only less frequent acquisition of user information from colleagues but no acquisition of information from user groups. An equally large segment of R\&D employees $(21.5 \%)$ experienced both frequent and less frequent acquisition of user information from different colleagues, as well as only less frequent acquisition of information from user groups. Of the responding R\&D employees, $7 \%$ experienced both frequent and less frequent acquisition of user information from colleagues but no information acquisition from user groups. A segment representing $2 \%$ of the responses experienced less frequent acquisition of user information from colleagues and both frequent and less frequent acquisition of information from user groups. An equal percentage (2\%) reported no acquisition of user information from colleagues and only less frequent acquisition of information from user groups. Of the responding R\&D employees, $5 \%$ had not acquired user information from colleagues or user groups. We now turn to descriptions and clarifications by the interviewees.

\subsection{Researcher (Node 17)}

The respondent has worked within the research groups for several years and is primarily working with the development and evaluation of new concepts. He perceives that, to some extent, it is a part of his job to seek information to understand what products the customer wants and he is visiting hospitals a few times a year. The respondent describes that it is essential to understand how the users intend to use a certain product and how the users' needs could be satisfied in the best way. He experiences that he receives very useful information from the physician that is incorporated in the research group since she has extensive experience of working in the clinical environment and has 
a broad network to other users. He describes that he is basically turning to her with any concern that he has related to the usage of the company's products. The main benefits of turning to her are that she is available and that he can receive quick answers, the closeness makes it simple. On a less frequent basis he also receives valuable input from other internal clinicians and to some extent he also receives valuable input about the users' needs from the marketing department. However, the input from the market department is mainly through their market reports. In general, he experiences that it takes time to learn about what knowledge different colleagues possess about users. He also experiences that he communicates more frequently with users at Swedish hospitals than with users in other markets, but at the same time he is aware that there are limitations in their views and that the users' behaviors differ between different countries and healthcare systems.

\subsection{Researcher (Node 19)}

The interviewee has worked for the company more than 25 years and is currently working within the research group. He experiences that it is a part of his job to learn about the users' needs. In general, he thinks that he has a quite good idea about what products the users want and he learns about the users' needs by continuously asking questions to internal and external clinicians. When he is asked to describe how he identifies people to talk to he answers that he is mainly using his experience and "feeling" and that it sometimes is necessary to ask more than one user to fully understand the users' needs and requirements related to a specific function. He emphasizes that this is the normal way for him to work and that it happens all the time. Furthermore, he also emphasizes that it is important to interact with users on different markets. In general, he experiences that he has more contact with national users but he also stresses that if there are users with specific knowledge that can be useful to the company then it does not matter where they are located. In such cases they find ways to interact. One relationship that he is frequently using to acquire information about the users' needs is the relationship to the physician that is incorporated in the research group. He emphasizes that it is her long experience of working in the clinical environment as well as the closeness that makes her useful. Much of their conversation has a rather informal nature and happens "in the breaks". He also acquires information from people within the sales and marketing department but this is on a less regular basis and more focused on commercial aspects.

\subsection{Internal clinician (Node 20)}

The respondent has worked for several decades as a physician and used the company's products on a regular basis. The respondent has also conducted research on the company's products and collaborated with the company on several projects. Eventually, there was an opening for her to start working for the company and so she "switched side". Initially she worked with clinical evaluations of new products but eventually she also got more and more involved in R\&D activities. The result of the questionnaire reveals that she is one of the most central actors in terms of disseminating user information to R\&D colleagues. She confirms that she has developed close relationships to several researchers and to some product developers that frequently turn to her to discuss new ideas and also to support them in the interpretation of standards and in doing risk assessments. Moreover, she experiences that the number of R\&D employees that are turning to her for advice has increased over the years as more and more people have learned that she possesses relevant and reliable experiences from the clinical environment.

\subsection{Internal clinician (Node 23)}

Prior to joining the company the respondent worked as a nurse for several decades and gained a lot of experience of working with the company's products in the clinical environment. His primary function is to teach other users about the company's products but he is also involved in product development projects. He is visiting hospitals in different countries on a regular basis and he perceives that he has a deep understanding of the clinical environment and the users' needs and requirements. The results of the questionnaire reveal that he is one of the most central persons in terms of disseminating user information to R\&D employees. This dissemination mainly occurs when he is involved in a specific project where he becomes "the eyes" towards the user community. However, he also explains that many of the relationships that he has developed to R\&D employees in these projects have been reused at later occasions when R\&D employees turn to him for advice. He experiences that the dialogues that he has with R\&D colleagues is highly valuable since they often result in functional solutions (from a user perspective). Moreover, he explains that it took some time to develop fruitful relationships to R\&D employees when he started at the company. He has also experienced how some R\&D employees are trying to use him and other users to triangulate information. 


\subsection{Researcher (Node 24)}

The respondent has been with the company for almost ten years and his current job is to manage the research group. To some extent, he experiences that it is a part of his job to have contacts with users and occasionally he visits hospitals. In general, he experiences a high value in interacting with users in different markets to develop an understanding of different user needs. He indicates the physician within the research group as a major source of user information. The main reason is that she has rather fresh experience from working in the clinical environment and that she is easy to access. Moreover, he also values that she has an extensive contact network with other users, which can be useful to find out about specific issues related to the use of the company's products. When he face an uncertainty related to the users' needs he normally turns to the internal physician for advice. Most of the time he gets a rather quick answer but in some cases the internal clinician turns to other users to find out more about a specific question. Moreover, he explains that this dialogue differs from the dialogue with marketers. He recalls that the conversation with marketers is more focused on developing a market requirement list and not on the specific usage of a product. He also confirms that he receives user information from a colleague in product development but he experience that their discussions have been more speculative. Furthermore, he confirms the result in the questionnaire by explaining that he rather frequently interacts with certain external researchers that possess some sort of expert knowledge related to the company's products. Moreover, he describes that he prefers to collaborate with users that are "down to earth" and can describe the practical clinical problems. Over the years he has learned to distinguish the users that are more academically oriented from the users that are more practically oriented.

\subsection{Manager of product development (Node 52)}

The respondent has worked as a project manager for several years within the development department. He does not experience that it is really part of his job to have contacts with users and he has only met (external) users at a few occasions when his groups has performed study trips to certain hospitals. Although he does not meet users on a regular basis he sees a great value in understanding how the products are being used. He experiences that he receives the majority of inputs about the users from knowledgeable colleagues. For instance, he confirms that he receives information about the usage of the products from one of the interaction designers. He also confirms that he receives valuable input about the users from one of his senior colleagues at the development department. At some occasions he has also been involved in useful discussions with the internal clinicians. He emphasizes that his search for user information is highly dependent on the stage of the project. For instance, he explains that it can be highly valuable to turn to an incorporated clinician or a senior colleague to talk about the users' needs when the requirements are specified. He experiences that it generally are less uncertainties related to the users' needs in the later stages of the development projects. Moreover, he describes that he mainly receives rather shallow information about the users' needs. It is mainly about developing a general understanding about how the products are being used.

\subsection{Systems architect (Node 61)}

The respondent has worked almost ten years for the company and is currently working as a systems architect. In his current position he does not have much contact with users but he has previously held positions within the organization where he had much customer contact. One essential competence that he developed in his previous position was to ask the right questions in the right situation to receive meaningful answers from the user. He also argues that he thinks it is valuable as a product developer to have contact with many different users since there are large differences between different markets. Even so, he confirms that one of the internal clinicians is a valuable source of user information and that they got to know each other when they where working together in a project. At some occasions he still turns to this internal clinician for advice. Most of the time he gets a direct answer to his questions. But he also recalls some situations where it has been essential to get the input from several users with different perspectives. He also confirms that he receives valuable user information from one of the marketers that he had worked with in several projects. However, he also explains that the information he receives from the marketers is more oriented towards the users' experience of the competitors' products. The internal clinicians are more concerned about clinical workflows and clinical performance. He also confirms that he has received valuable information at some occasions from interaction designers within the company.

\subsection{Interaction designer (Node 62)}

The respondent has worked for several years within the business unit as an interaction designer. It is a part of her job to have contacts with users and she acquires user information at all stages of the product development process. Overall, she experiences that she has a good understanding of the users' needs and priorities. However, she also explains that she does not have direct use experience from the clinical environment. For this reason she frequently turns to the internal clinicians for advice. When confronted with the results from the questionnaire she confirms that 
there is especially one internal clinician that she has been working closely with in several projects. They have a quite informal collegial relationship that has developed over the course of many years. Most of the times she turns to the internal clinician to understand how certain clinical procedures are carried out and how the users think in certain situations. She describes the relationship as a highly important "tool" for her to accomplish her job. Moreover, she experiences that the information she receives from the internal clinician has a certain depth and is often rather specific. She also confirms that she uses other relationships to access user information and explains that their background and professional roles largely influence to what extent she turns to them for advice about the users' needs. She also confirms that she occasionally turns to sales people for advice but her experience is that they normally provide her with a more general knowledge about the users' needs and requirements. Knowing about different people's background and use experience also helps her to judge if she has to triangulate the input with other users. In terms of utilizing the information she explains that it normally is easier to generate good ideas with people that she has been working with for some time although less frequent relationships can provide new perspectives.

\subsection{Systems architect (Node 64)}

The respondent has worked at the company for ten years and is currently working as a systems architect within the product development department. He has previously worked within the research group. In his previous position he had more contact with users and experiences that he has now become a bit more peripheral in his relation to the users. The respondent confirms that one of the most central sources of "everyday" user information is one of the internal clinicians and they have worked together in several projects. In these projects he also collaborated with some of her previous colleagues at hospitals. This relationship has been utilized to accomplish several things like for instance defining functionality and verify new ideas. In many cases he uses this relationship to understand what functionality is good enough and to derive some objective and quantifiable information as well as the users' preferences in the clinical environment. However, he also explains that he sometimes also decides to triangulate the information he receives with other users since he knows that different users can have slightly different behaviors and opinions about what solutions they want. He also confirms that he acquires user information from marketers and product management. However, he recalls that this information has a more commercial nature. In his view marketers and product managers want to define a product that they can sell, whereas users want to develop a product that they want to use.

\subsection{Manager of product development (Node 70)}

The respondent has worked for the company for more than a decade and is currently manager for a unit within the product development department. She does not recall that it is part of her job to have contact with users and she experiences that her knowledge about the users' needs is rather shallow. In her job she largely relies on the information that is gathered by the market department. Over the last years she has visited hospitals occasionally but has mainly been stationed in-house. She confirms that she has received valuable information from internal clinicians on an occasional basis, mainly in relation to specific projects where they have been collaborating. Although she does not work with them today she occasionally turns to them for advice. The main reason is to get the internal clinicians help to interpret certain standards and define the requirement list for a particular product. She experiences that the information that she receives about the users' needs is quite shallow and argues that this is mainly due to her own lack of understanding of the users' needs.

\subsection{Manager of product development (Node 85)}

The respondent has been at the company for almost ten years and is currently working as a software development manager. In this position he experiences that he has limited contacts with users. However, he previously worked within the interaction design group where he was involved in more user collaboration activities. During this time he learned a lot about the type of user-related knowledge that clinicians and interaction designers possess. He also learned about the importance to acquire information from users at different markets when developing a product. He confirms that he has received valuable information from some of the internal clinicians but emphasizes that these contacts were more intense when he held his previous position. However, he also emphasizes that he also receives valuable information from some of the researchers. These relationships are described as highly valuable and without these relationships he would simply be guessing about the users' needs. Furthermore, these relationships are described as informal and it is emphasized that the instant access is critical to utilize these relationships. Moreover, he explains that he utilizes these relationships differently in different phases of the development process. 


\section{Analysis}

To start with the results reveal that there are large differences between different R\&D employees. Some R\&D employees (node 19,62, and 64) have rather comprehensive networks through which they access valuable user information. Other R\&D employees have a very limited number of relationships for this purpose (node 52 and 85 ). Several explanations for these differences can be induced from the result. One reason is that the use of relationships to access user information is closely linked to the tasks that employees are working with. In line with the observation of Gales and Mansour-Cole (1995) those employees that are working with tasks that have a high degree of uncertainty and ambiguity related to the users' needs tend to establish more proficient relationships to access user information (node 24 or 62). Some respondents even describe that they are directly dependent on these relationships and that the relationships are an important "tool" for them to solve the tasks that they are assigned. Moreover, the interviews indicate that there are differences between product developers and researchers in the way they use their social networks to acquire and exploit user information. Product developers (node 52 and 70) tend to use their relationships in specific stages and for specific tasks in product development projects. In contrast to this, researchers (node 17, 19, 24 ) tend to use their social networks more spontaneously as they explore new ideas and concepts.

The results also show that whether employees' search for user information is highly dependent on previous experiences. For instance, several respondents describe how they have developed relationships to internal clinicians through the collaboration in specific product development projects. These relationships are then re-used after the project is finished. The results display how R\&D employees become more knowledgeable over time concerning where different types of user knowledge can be found, and how they use their social networks to access this knowledge in order to solve specific tasks. For instance, several respondents describe how they acquire different types of user information from employed clinicians, marketers, interaction designers, physicians, and clinical researchers. Furthermore, the results display how R\&D employees with extensive experience of searching for user information have developed their skills to ask the "right" questions, evaluate user information critically, and triangulate user information if necessary. Moreover, their search for user information is not only related to their valuation of the knowledge held by colleagues and users but also to their valuation of these individuals' contacts to other sources of user information (node 17 and 24). These observations complement previous work on how R\&D employees develop their user interaction competence and how this competence is used to access information about the users needs and priorities (Lettl, 2007; Adams et al., 1998).

Previous research reveals that valuable knowledge can be created in strong relationships (Hansen, 1999). The results presented in this paper support this observation. Several R\&D employees recall how they have developed close relationships to internal clinicians that have been highly valuable for the development of valuable knowledge as well as novel ideas (node 17, 19, and 24). The internal clinicians' extensive use experience, their contacts with other users, their availability, and their willingness to discuss new ideas tend to promote the emergence of strong relationships to R\&D employees. However, an important observation is that these relationships develop over time. Both of the internal clinicians interviewed explained that it had taken time to develop fruitful relationships to R\&D employees. Moreover, R\&D employees who had been interacting with the internal clinicians on a regular basis experienced that they acquired deep and specific user information from these relationships (node 62 and 64). In difference, R\&D employees who interacted with the internal clinicians on a more occasional basis recalled that they had received rather shallow information about the users needs from these interactions (node 52 and 70). In line with Daft and Lengel (1986) and Zaheer et al. (1998) the reciprocal and confidence-inspiring communication between certain R\&D employees and the internal clinicians resulted in a very rich communication. However, the results of this investigation also display how new user contacts and weak relationships provide R\&D employees with novel information and new perspectives, especially from users outside the Swedish market (node 17, 19, 24, 61, and 85). This part of the result supports the idea that there is strength also in weak relationships (Granovetter, 1973; Burt, 2004).

\section{Discussion}

This article set off to investigate how R\&D employees acquire user information through their social networks and how they use this information in new product development. The article has implications for several theoretical fields. To start with, the article has implications for the literature on absorptive capacity. Resent research argues that it is necessary to not only focus on the R\&D function but also other functions when assessing companies' absorptive capacity. For instance, Bogers and Lhuillery (2012) argue that companies' marketing-based sources influence how they absorb external information. This notion, that market information processing plays an important role in new product development, also finds support in other parts of the literature (Griffin and Hauser, 1996; Leenders and Wierenga, 2002). However, these streams of literature are highly focused on the role of marketing departments and 
mainly concern the handling of market information (i.e. information about customers and competitors). This article instead shows that companies may benefit from a more explicit focus on their sources of direct and indirect use experience. Indeed, the results reveal that many R\&D employees establish strong relationships to people with extensive use experience (in this case incorporated clinicians) from whom they can access information in a timely and cost-efficient manner. The results also show that the information that R\&D employee's access from people with direct use experience is significantly different from the type of knowledge they receive from people with indirect use experiences (like for instance marketers or interaction designers).

Moreover, this article makes a contribution to the literature on user involvement in new product development. A majority of this research concerns project-based interactions and collaborations with users (Lüthje and Herstatt, 2004; Lillien et al., 2002; Gruner and Homburg, 2000; Gales and Mansour-Cole 1995). Indeed, this article supports the notion that sufficient user involvement is essential to succeeding with new product development projects. However, the article also expands the view on user relationships arguing that it is essential to consider not only R\&D employees' user relationships within specific product development projects but also to consider more long-term relationships that are used in many different projects. This finding is consistent with the hypothetical argumentation in recent articles proposing that leading-edge users can add value in more than just one innovation project and that companies consequently can benefit from adopting a more long-term perspective on these relationships (Keinz et al., 2012). Moreover, the results largely confirm the observations by Lettl (2007) and Adams et al. (1998) that some R\&D employees develop certain user interaction competences. However, a related insight from this article is the notion that this competence has a highly cumulative nature and that it is developed through the continuous interaction with people holding various direct and indirect use experiences.

The results also reveal that many R\&D employees that are facing high levels of uncertainty and ambiguity related to the users' needs are using both strong and weak relationships to access timely and reliable user information in the new product development process. The R\&D employee's cost-efficient access to persons with extensive use experience drives the development strong relationships where the use experience continuously is integrated with various types of solution knowledge. These relationships can be highly valuable for R\&D employees' "everyday" acquisition and exploitation of user information. However, as these relationships develop over time R\&D employees also become aware of the limitations in the persons use experience and complements this relationship with other, more occasional, relationships to other sources of direct and indirect use experiences. Nevertheless, in some cases the person in the strong relationship (for instance an internal clinician) has such high levels of self-revelation that they support their colleagues in R\&D to find appropriate sources of information about the users needs and priorities.

Based on the results of this study the authors propose a number of managerial implications. To start with, the results show how important it is that management provides opportunities for innovating R\&D employees to establish and utilize relationships conducive to information about the users' needs. This can be accomplished in many different ways, like for instance field trips, user workshops, inviting users to the R\&D site, establish relationships with users at different markets that employees' can contact, or employing users with extensive experience of using the company's products. One important notion is that management should facilitate the creation of relationships to users with heterogeneous use experiences. Moreover, management should not solely facilitate project-specific user relationships but also encourage employees to develop more long-term relationships to people with extensive and valuable use experience. Moreover, the results show that certain dyadic relationships between experienced users and R\&D employees can be highly fruitful in terms of generating ideas for innovation. Thus, managers can pay attention to these types of relationships emerge and provide the focal employees with means to nurture their relationships. For instance, if an engineer and a user develop a relationship that generates a large number of high quality ideas management can provide them with resources and time to continue to work together.

Moreover, the results reveal that R\&D employees, at least to some extent, tend to bring their user relationships when they move to other positions or new projects. Hence, this can be an important consideration for managers when project groups are being formed. To bring in a person with proficient use experience and/or contacts with users can be a means to increase the likelihood that the project will actually deliver fruitful outcomes. Furthermore, the results display that R\&D employees that frequently use their social networks to access user information possess three typical characteristics. Firstly, they tend to be aware of their shortcomings in terms of their understanding of what product the user actually wants, and are curious to learn more about the user and the contexts in which the products are supposed to be used. Secondly, they have learned over the course of many years where different types of user knowledge reside, within and outside the organization, and how they can use these knowledge sources to solve innovation-related tasks. Thirdly, they have developed certain interaction competences, which allow them to efficiently derive valuable user information. Consequently, managers can initiate training programs for R\&D employees where they can learn and practice these skills. 


\section{Conclusions}

This article set out to investigate how R\&D employees acquire user information through their social networks and how this information is used in new product development. Based on the results it can be concluded that the relationships that are established between R\&D employees and people with use experience play an important and sometimes even critical role in the development of new products. However, the article also displays that our existing understanding of these relationships is somewhat incomplete with regards to how these relationships are established, what their characteristics are, and how they are utilized. Essentially, these relationships and networks represent critical bridges between the company and its user community. At the same time, this article raises questions concerning the definition of the boundary between companies and their user communities. It seems as though the traditional view where companies and users are more or less separated and only interact during certain product development activities is no longer fully applicable. As a response to this, it can be proposed that the interface between companies and their user community can be understood as an overlapping membrane built up by inter-personal relationships between people holding direct or indirect use experiences and people holding some sort of solution knowledge. Hence, this usercompany borderland tends to have the characteristics of a distributed knowledge system (see Tsoukas, 1996) where innovating R\&D employees establish and utilize cost-efficient relationships to people that possess relevant use experiences.

\section{Limitations and future research}

Based on the findings in this study, the authors see a number of areas of interest for future research. To start with, a limitation of this study is the fact that it is based solely on one firm's R\&D unit. Consequently, it is difficult to evaluate how representative the findings are to other R\&D organizations in other industries. It would be interesting to investigate and compare these results with R\&D units in other industries and cultural settings. Secondly, the authors did not have the opportunity to verify R\&D employees' interaction with "external" users. Thus, an interesting direction for future research would be to investigate the relationships that R\&D employees establish with users outside the company and how these relationships are utilized over time. Thirdly, our investigation solely focused on the handling of user information. Future research could combine this approach with an investigation of relationships conducive to technological information and knowledge.

\section{References}

Adams, M. E., Day, G. S. and Dougherty, D. (1998), "Enhancing new product development performance: an organizational learning perspective", Journal of Product Innovation Management, Vol. 33, No. 5, pp. 403-422.

Ahuja, G. (2000), "The duality of collaboration: Inducements and opportunities in the formation of interfirm linkages" Strategic Management Journal, Vol. 21, No. 3, pp. 317-343.

Allen, T. J. (1977), "Managing the flow of technology: Technology transfer and the dissemination of technological information within the R \& D organization", Mass., MIT Press, Cambridge.

Allen, J., James, A. D. and Gamlen, P. (2007), "Formal versus informal knowledge networks in R\&D: a case study using social network analysis", R\&D Management, Vol. 37, No. 3, pp. 179-196.

Argote, L. and Miron-Spektor, E. (2011), "Organizational learning: From experience to knowledge", Organization Science, Vol. 22, No. 5, pp. 1123-1137.

Bacon, G., Beckman, S., Mowery, D. and Wilson, E. (1994), "Managing product definition in high-technology industries: a pilot study", California Management Review, Vol. 36, No. 3, pp. 32-56.

Bogers, M., Afuah, A. and Bastian, B. (2010), "Users as innovators: a review, critique, and future research directions", Journal of Management, Vol. 36, No. 4, pp. 857-875.

Bogers, M. and Lhuillery, S. (2011), "A functional perspective on learning and innovation: Investigating the organization of absorptive capacity", Industry and Innovation, Vol. 18, No. 6, pp. 581-610. 
Borgatti, S. P. and Cross, R. (2003), "A relational view of information seeking and learning in social networks", Management Science, Vol. 49, No. 4, pp. 432-445.

Borgatti, S.P., Everett, M.G. and Freeman, L.C. (2002), "Ucinet 6 for Windows: Software for Social Network Analysis", Harvard, MA: Analytic Technologies.

Burt, R. S. (2004), "Structural holes and good ideas", American Journal of Sociology, Vol. 110, No. 2, pp. 349-399.

Cohen, W. M. and Levinthal, D. A. (1990), "Absorptive capacity: a new perspective on learning and innovation" Administrative Science Quarterly, Vol. 35, No. 1, pp. 128-152.

Cooper, R. G. and Edgett, S. J. (2008), "Maximizing productivity in product innovation”, Research-Technology Management, Vol. 51, No. 2, pp. 47-58.

Cooper, R. G. and Kleinschmidt, E. J. (1994), "Determinants of timeliness in product development", "Journal of Product Innovation Management", Vol. 11, No. 5, pp. 381-396.

Cross, R. L. and Parker, A. (2004), "The hidden power of social networks: Understanding how work really gets done in organizations", Harvard Business Press.

Daft, R. L. and Lengel, R. H. (1986), "Organizational information requirements, media richness and structural design", Management Science, Vol. 32, No. 5, pp. 554-571.

Dosi, G. (1988), "Sources, procedures, and microeconomic effects of innovation", Journal of Economic Literature, Vol. 26, No. 3, pp. 1120-1171.

Eisenhardt, K. M. (1989), "Building theories from case study research", Academy of Management Review, Vol. 14, No. 4, pp. 532-550.

Freeman, C. and Soete, L. (2009), "Developing science, technology and innovation indicators: What we can learn from the past", Research Policy, Vol. 38, No. 4, pp. 583-589.

Gales, L. and Mansour-Cole, D. (1995), "User involvement in innovation projects: toward an information processing model”, Journal of Engineering and Technology Management, Vol. 12, No 1, pp. 77-109.

Granovetter, M.S. (1973), "The Strength of Weak Ties”, The American Journal of Sociology, Vol. 78, No. 6, pp. 13601380.

Griffin, A. and Hauser, J. R. (1996), “Integrating R\&D and marketing: a review and analysis of the literature”, Journal of Product Innovation Management, Vol. 13, No. 3, pp. 191-215.

Gruner. K.E. and Homburg. C. (2000), "Does Customer Interaction Enhance New Product Success?", Journal of Business Research, Vol. 49, No. 1, pp. 1-14.

Hansen, M. T. (1999), "The search-transfer problem: The role of weak ties in sharing knowledge across organization subunits", Administrative Science Quarterly, Vol. 44, No. 1, pp. 82-111.

Keinz, P., Hienerth, C. and Lettl, C. (2012), "Designing the Organization for User Innovation", Journal of Organization Design, Vol. 1, No. 3, pp. 20-36.

Krackhardt, D. (1992), "The strength of strong ties: The importance of philos in organizations", Networks and organizations: Structure, form, and action, 216, 239.

Leenders, M. A. and Wierenga, B. (2002), "The effectiveness of different mechanisms for integrating marketing and R\&D”, Journal of Product Innovation Management, Vol. 19, No. 4, pp. 305-317.

Lettl, C. (2007), "User involvement competence for radical innovation", Journal of Engineering and Technology Management, Vol. 24, No. 1, pp. 53-75. 
Liebeskind, J. P., Oliver, A. L., Zucker, L. and Brewer, M. (1996), Social networks, learning, and flexibility: Sourcing scientific knowledge in new biotechnology firms, Organization Science, Vol. 7, No. 4, pp. 428-443.

Lilien, G. L., Morrison, P. D., Searls, K., Sonnack, M. and von Hippel, E. (2002), "Performance assessment of the lead user idea-generation process for new product development", Management Science, Vol. 48, No. 8, pp. $1042-1059$.

Lilleoere, A. M. and Hansen, E. H. (2011), "Knowledge-sharing enablers and barriers in pharmaceutical research and development", Journal of Knowledge Management, Vol. 15, No. 1, pp. 53-70.

Lind, M. R. and Zmud, R. W. (1991), "The influence of a convergence in understanding between technology providers and users on information technology innovativeness", Organization Science, Vol. 2, No. 2, pp. 195-217.

Lüthje, C. and Herstatt, C. (2004), "The Lead User method: an outline of empirical findings and issues for future research", R\&D Management, Vol. 34, No. 5, pp. 553-568.

Nonaka, I., Takeuchi, H. and Umemoto, K. (1996), "A theory of organizational knowledge creation", International Journal of Technology Management, Vol. 11, No. 7, pp. 833-845.

McDermott, R. and O'Dell, C. (2001), "Overcoming cultural barriers to sharing knowledge”, Journal of Knowledge Management, Vol. 4, No.1, pp. 76-85.

Pfeffer, J. and Salancik, G. R. (1978), "The external control of organizations: A resource dependence approach", NY: Harper and Row Publishers.

Schulze, A. and Hoegl, M. (2008), "Organizational knowledge creation and the generation of new product ideas: A behavioral approach”, Research Policy, Vol. 37, No. 10, pp. 1742-1750.

Tsoukas, H. (1996), "The firm as a distributed knowledge system: a constructionist approach", Strategic Management Journal, Vol. 17, pp. 11-25.

Veryzer, R. W. (1998), "Discontinuous innovation and the new product development process", Journal of Product Innovation Management, Vol. 15, No. 4, pp. 304-321.

Volberda, H. W., Foss, N. J. and Lyles, M. A. (2010), "Perspective - absorbing the concept of absorptive capacity: How to realize its potential in the organization field", Organization Science, Vol. 21, No 4, pp. 931-951.

von Hippel, E. (1986), "Lead users: a source of novel product concepts", Management Science, Vol. 32, No. 7, pp. 791-805.

von Hippel, E. (1994), "Sticky information" and the locus of problem solving: implications for innovation", Management Science, Vol. 40, No. 4, pp. 429-439.

von Hippel E. (2005), Democratizing Innovation: Users Take Center Stage. MIT Press: Boston, MA.

von Hippel, E., Thomke, S. and Sonnack, M. (1999), "Creating breakthroughs at 3M", Harvard Business Review, Vol. 77, pp. 47-57.

Wadell, C., Ölundh Sandström, G., Björk, J. and Magnusson, M. (2013), "Exploring the incorporation of users in an innovating business unit", International Journal of Technology Management, Vol. 61, No. 3, pp. $293-308$.

Zaheer, A., McEvily, B. and Perrone, V. (1998), "Does trust matter? Exploring the effects of interorganizational and interpersonal trust on performance", Organization Science, Vol. 9, No. 2, pp. 141-159. 